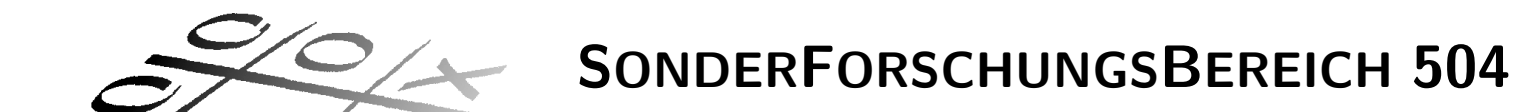

Rationalitätskonzepte,

Entscheidungsverhalten und

ökonomische Modellierung

\begin{tabular}{|c|} 
No. 08-17 \\
Non-Profit Organizations in a Bureaucratic \\
Environment \\
Paul Grout* \\
and Wendelin Schnedler** \\
\end{tabular}

September 2008

Financial support from the Deutsche Forschungsgemeinschaft, SFB 504, at the University of Mannheim, is gratefully acknowledged.

*University of Bristol, Department of Economics, email: P.A.Grout@bristol.ac.uk

** Department of Economics, University of Heidelberg, email: wendelin.schnedler@awi.uniheidelberg.de

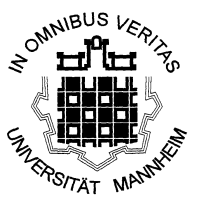

Universität Mannheim

L 13,15

68131 Mannheim 


\title{
Non-Profit Organizations in a Bureaucratic Environment
}

\author{
Paul Grout \\ Department of Economics \\ University of Bristol
}

\author{
Wendelin Schnedler* \\ Department of Economics \\ University of Heidelberg
}

September 1, 2008

\begin{abstract}
How does the environment of an organization influence whether workers voluntarily provide effort? We study the power relationship between a non-profit unit (e.g. university department, NGO, health trust), where workers care about the result of their work, and a bureaucrat, who supplies some input to the non-profit unit, but has opportunity costs in doing so (e.g. Dean of faculty, corrupt representative, government agency). We find that marginal changes in the balance of power eventually have dramatic effects on donated labor. We also identify when strengthening the non-profit unit decreases and when it increases donated labor.
\end{abstract}

Keywords: donated labor, intrinsic motivation, non-profit organizations, power within organizations

JEL-Codes: J32, H11, H42, M52

${ }^{*}$ Universität Heidelberg, Alfred-Weber-Institut, Grabengasse 14, 69117 Heidelberg, Germany. (wendelin.schnedler@awi.uni-heidelberg.de). In its early stages, the paper has benefited from comments at the AEA meeting in Chicago 2007. 


\section{Introduction}

Individuals are often willing to sacrifice time and effort because they care about the results of their work; they engage in some form of pro-social behavior (Benabou and Tirole, 2006). The question of how to set up an organization and provide incentives in the presence of such individuals has sparked considerable interest amongst economists (see David Easley and Maureen O'Hara 1983, Patrick Francois 2000, Edward L. Glaeser and Andrei Shleifer 2001). Little attention has been paid, however, to the influence of the context in which the organization operates. Does this context affect the labor donated by members of the organization and if so, how? In this article, we consider an organization in which workers are willing to donate labor (non-profit unit) and study the effect of its context on donated labor.

Our main result is that marginal changes in this context will at some point have a discrete effect on donated labor. This finding results from the interaction of two relatively generic characteristics of bureaucratic environments. First, the non-profit unit depends on external contributions that are controlled by a bureaucrat whose interests are not aligned with the non-profit unit. Second, there are almost always informal ways to undermine and attempt to overturn the bureaucrat's decision. We show that in the presence of these two characteristics, a gradual change can alter whether the threat to exploit informal ways is credible and thus shift the nature of incentives. Both to elucidate the two characteristics and as a motivating device for the analysis, it is useful to identify some specific examples of our general approach.

One obvious semi-bureaucratic environment that academics are very familiar with is the position of a department within a university. The depart- 
ment's quality depends on labor input and contributions from the university, which are, let us assume, in the control of the Dean of the Faculty. The members of the department are primarily concerned with the quality of the output of their department. The Dean, however, has other departments to oversee. The Dean may promise to reward efforts by the department in developing a valued output (e.g., a successful research center, etc.), but ultimately she acts opportunistically and uses the pledged contributions in the interest of the faculty and not in that of the department. On the other hand, the department can try to undermine the Dean and obtain more resources, e.g. by lobbying the University President. This option, however, is costly, takes time, and the outcome is uncertain. The Dean will be aware of the difficulties a department faces in attempting to undermine her position but the scope for undermining may still impinge on her choice. Thus, the equilibrium level of the Dean's support and in turn the donated labor in the department is determined by the interaction of two features: the Dean's discretion and the scope for undermining her decision.

As another somewhat similar type of example, consider a non-governmental organization (NGO) working on the ground in a developing country. The activity on the ground may depend on labor effort from the NGO workers as well as contributions from an international organization. Imagine that a corrupt local representative distributes resources on behalf of the international organization. This representative may care about the help provided by the NGO but also benefit from diverting some resources away from their intended purpose (e.g. to another village to which she has closer ties). The workers in the NGO who prefer that resources are sent where they are most needed 
may be able to bring some pressure to bear on the representative by lobbying and complaining to the international organization. So, how much the representative diverts may depend on the effectiveness of the NGO in operating within the bureaucratic structure of the international organization.

Identical features also arise in an apparently very different market setting. Here, think of the non-profit organization producing an item of variable quality for a potential 'customer.' Quality depends on labor and other inputs, with the other inputs being paid for from revenue. Due to the non-profit status, all the revenue obtained from sales is used to fund the other inputs. Assume that the market is not perfectly competitive and that the customer can set a price. The customer has no interest in pushing the price down to zero because this means that the non-profit organization has no funds for the other inputs and quality will be low. Still, the suggested price may be well below the value of the output. If the non-profit organization finds the price unsatisfactory, it can seek out another prospective customer, play off the two customers, and obtain a price that equals the value of the good. However, it is not certain when and whether this alternative can be found. Consequently, the customer's suggested price and hence the donated labor within the non-profit organization depends on the interaction of the same two features: the customer's flexibility in setting the price and the non-profit organization's (costly) option to overturn this offer. An advantage of this example is that the behavior of the customer and the price obtained when a second customer arrives can be derived in a market framework, so that the example is formally more 'tied down.'

In each example, the agent who decides on contributions (The Dean, cor- 
rupt official, or customer, henceforth: bureaucrat) has some discretion that may be curbed by appealing to an authority (university principal, international organization, or the market). These two features result from some fundamental contracting problem: the difficulty to specify a product or service and its inputs in such a way that they can be verified by a court of law. ${ }^{1}$ Avinash Dixit (2002) argues that this difficulty explains why certain products are not traded on markets but provided within a bureaucratic structure. The vague character of the product necessarily implies that bureaucrats have some discretion (our first feature). In most cases, they are answerable to a superior and thus restricted (our second feature). The two features thus seem almost generic in any bureaucratic structure. Our main result is that their presence creates a discontinuity in donated labor.

The intuition for the presence of a discontinuity relies on two observations. First, incentives to donate labor are different depending on whether the threat by the non-profit unit to appeal to the authority is credible or not. Secondly, whether this threat is credible is affected by the context of the non-profit unit. Consequently, a slight change in the context can render the threat to appeal implausible, shift the type of incentives, and affect donated labor dramatically.

In order to illustrate this intuition in more detail, let us return to the market example. First, consider the case that waiting for another customer is not credible. Then, the customer can save money without reducing quality

\footnotetext{
${ }^{1}$ As an example, take the 'product' description by Greenpeace which aims to "improve and preserve the environment and the ecology of planet Earth' or that by Sutter Health, a non-for profit health provider in California, which strives to "demonstrate the highest levels of quality care and service."
} 
by cutting the price whenever the non-profit organization puts in more effort. ${ }^{2}$ Now turn to the case where the threat is credible. Then, more effort at the non-profit unit increases the value of the product and the customer is forced to pay a higher price in order to keep competing buyers at bay. Therefore, larger effort commands a higher price if waiting for an alternative buyer is credible, but not otherwise. Put differently, incentives to donate labor are enhanced if the non-profit organization is in a strong position and they are dampened otherwise. Suppose now that the balance of power slightly changes, for example, the non-profit organization may find it somewhat easier to seek out an alternative. Then, the gain in power will at some point induce a shift from a regime where donated labor is punished to a regime where it is rewarded. The ensuing change in margins then implies a dis-continuous boost in donated labor.

While this simple example illustrates the mechanism, not all of its features are essential for the discontinuity. In particular, it is not necessary that donated labor is rewarded if the threat is credible and punished otherwise. The key idea is that incentives shift. For such a shift it suffices that bureaucrat (e.g. the customer) and authority (e.g. the market) respond differently to an increase in donated labor. However, if there is additional information on how bureaucrat and authority react to more donated labor, we can predict whether donated labor falls or increases. For example, the authority may reward additional effort by a larger relative increase in contributions than the bureaucrat, so that contributions set by the authority are more elastic in

\footnotetext{
${ }^{2}$ This idea is reminiscent of the expropriation of workers in for-profit firms put forward by Francois (2000) and Glaeser and Shleifer (2001).
} 
donated labor. Then, a stronger stance of the non-profit unit results in an increase of donated labor.

Our paper contributes to the growing literature on incentives when agents are intrinsically motivated. This literature asks how to attract such agents (Tim Besley and Maitreesh Ghatak, 2005), how to structure an organization in the presence of such agents (David Easley and Maureen O'Hara, 1983, Patrick Francois, 2000, Edward L. Glaeser and Andrei Shleifer, 2001) and whether to provide explicit incentives to them. ${ }^{3}$ Our article is particularly close to Francois (2000) as well as Glaeser and Shleifer (2001) who observe that non-profit status protects the interests of employees and thereby ensures that they remain motivated. In contrast, we take the analysis beyond the bounds of the organization. We show that the context of an organization has interesting repercussions for the motivation within that organization.

The remainder of the paper is organized as follows. The next section introduces the model. In Section 3, we analyze this model and present the formal results. Section 4 concludes with a discussion of key assumptions, their applications and implications.

\section{Model and Notation}

In this section, we present the model and introduce some useful definitions.

\footnotetext{
${ }^{3}$ Uri Gneezy and Aldo Rustichini, 2000, Armin Falk and Michael Kosfeld, 2006, Dirk Sliwka, 2006, Roland Bénabou and Jean Tirole, 2003, Guido Friebel and Wendelin Schnedler, 2007, Schnedler and Radovan Vadovic, 2007, Tore Ellingsen and Magnus Johannesson, 2008.
} 


\section{$2.1 \quad$ Model assumptions}

The model has two main players: a worker at a non-profit unit (he), and a bureaucrat (she). The worker is hired at a wage $w$ by the non-profit unit and provides more or less effort. The bureaucrat decides on how much assistance she is willing to give to the non-profit unit. She may, for example, hold back or divert donated material. More generally and more concisely, we say that the bureaucrat contributes to the product. Generally, the effort by the worker and the contributions by the bureaucrat may have aspects that can be stipulated in a contract and enforced by a court of law. We assume that such contracts are used wherever this is possible, and focus our analysis instead on the effort $e$ and contribution $q$ which cannot be implemented by contracts.

Effort and contribution. The worker's effort $e$ is costly and comes from a compact interval. Effort costs $c$ are convex and increase in $e$ while $c^{\prime}(0)=0$. Likewise, contributions $q$ entail opportunity costs $k$ for the bureaucrat that are increasing and non-concave in $q$ with $k^{\prime}(0)=0$. Effort and contributions both strictly increase the value $v$ of the product. On the other hand, a higher wage $w$ decreases this value because it reduces the resources available for production. Overall, $v$ is a function of effort, contributions and wage, $v(e, q, w)$, which we assume to be concave in all three arguments.

Worker's utility. The worker in our model does not only care about effort costs $c$ and his wage $w$ but also about the value $v$ of the product. This genuine interest in the result of his work may be due to other-regarding preferences, ideals, or professional attitude. His utility amounts to: $\alpha v(e, q, w)-c(e)+w$, where $\alpha>0$ measures the degree to which the worker cares about the value. Despite effort costs, the worker may thus exert effort. We want to focus 
on the case in which the worker donates his labor rather than his money. Accordingly, we assume that the effect of a reduction in wage on the value is limited $\left(\left|\frac{\partial v(e, q, w)}{\partial w}\right|<\eta\right)$ and too small in relation to the foregone earnings $\left(\alpha<\frac{1}{\eta}\right)$.

Bureaucrat's utility. Let the bureaucrat's utility be: $\beta v(e, q, w)-k(q)$ with $\beta>0$. The particular form is chosen to simplify the exposition. It features, however, two important aspects. First, the bureaucrat cares to some degree about the value of the product. The interest in the value of the product does not have to result from altruism or idealism. The value may, for example, matter to the bureaucrat because her reputation is at stake or because the project bestows prestige on her. If the bureaucrat did not care at all, she would use all resources for herself. Under these circumstances, the question of whether to appeal to an authority becomes trivial as an appeal can only lead to larger contributions. Formally, all that is required is that the (unrestricted) maximization problem of the bureaucrat's utility has an inner solution. ${ }^{4}$ Second, the contribution that maximizes the bureaucrat's utility is continuous in effort. This ensures that any discontinuity results from the structure of the game and is not due to ill-behaved fundamentals.

Manager of non-profit unit. So far, our model features two players: the worker at the non-profit unit and the bureaucrat who does not belong to this unit. In the literature, there is often a second player within the worker's organization: a manager whose behavior affects workers' incentives. In a

\footnotetext{
${ }^{4}$ Alternatively, we could impose any other utility function with this property. For example, the bureaucrat could be promoted if the project is successful while the gains from promotion exceed the opportunity costs of diverting all contributions.
} 
for-profit firm, the manager/owner acts as a residual claimant and destroys these incentives. In a non-profit organization, it is not possible to expropriate workers and incentives remain intact. In order to link up with this literature, we introduce such a manager, although he is not central to our model. In particular, he has no negative effect on the worker's incentives because he is not the owner. Still, the manager helps us to close our model: he negotiates with the worker about the wage and with the bureaucrat about contributions. For simplicity's sake, we assume that the manager is solely interested in the resources that are available for production. A reason may be that the manager benefits from these resources in form of perks, private benefits, etc. Formally, the manager obtains a share from contributions $q$ as well as from money saved due to a lower wage bill $w$. The manager discounts payoffs arising at $\tau$ by $e^{-r \tau}$.

Opportunities to overturn. The manager of the non-profit unit as well as the worker want contributions to be as large as possible. This is not true for the bureaucrat who desires to divert at least some of the contributions. Interests of the non-profit unit and the bureaucrat are hence partially conflicting and to complete our model, we need to specify how this conflict is resolved. In line with the initial examples, the bureaucrat is a 'local' monopolist and can set the contribution level. Her power, however, is curbed by the context. If the manager considers contributions to be too low, he can wait for an opportunity to overturn the bureaucrat's decision. This opportunity could be a successful conversation with the vice-chancellor in the university example, finding a powerful official in the international organization in the NGO example, or the arrival of a competitor in the market example. Sup- 
pose that such opportunities are distributed exponentially and arrive at rate $\theta$. Then, $\theta$ can be conveniently interpreted as the negotiation or lobbying skills of the manager or more generally as the power of the non-profit unit to overturn the bureaucrat's decision.

Authority. If the opportunity arises, the choice by the bureaucrat is overturned and the contribution is determined by an authority. In the university and NGO example, the authority are the vice-chancellor and the powerful official. In the market example, the authority is the market itself. In the latter case, it is straightforward to determine what level of contribution $q^{A}$ will be set by the authority (here: the market). Given the arrival of a competitor, the non-profit unit can play off the two. Bureaucrat and competitor will increase contributions up to the point where this is no longer possible. Accordingly, the contribution $q^{A}$ in this case is implicitly defined by $v\left(e, q^{\mathrm{A}}(e), w\right)=k\left(q^{\mathrm{A}}(e)\right)$. Generally, we assume $q^{A}$ to be a continuously differentiable function of effort. Again, we do so to highlight that the fundamental functions are well-behaved and exhibit no discontinuities.

Timing. The sequence of events is the following:

1. The manager offers the worker a wage $w$ and

2. the worker decides whether to accept or take on some outside opportunity that yields utility $\underline{u}$. If he rejects the game ends. Otherwise

3. the worker decides on effort $e$,

4. the bureaucrat makes an offer to contribute $q$ and

5. the manager of the non-profit unit may accept this offer or wait for the (stochastically arising) opportunity to implement $q^{\mathrm{A}}$. 
Payoffs accrue whenever the contribution is determined. This could be either because the offer by the bureaucrat is undisputed or because contributions are implemented by the authority.

\subsection{Contributions of an unfettered bureaucrat}

The key idea of our model is that the bureaucrat's discretion is limited. Still, it is useful to consider the benchmark case in which the bureaucrat's power is unlimited. In this case, she simply maximizes her utility and contributions take on the following level.

$$
q^{\mathrm{B}}(e):=\operatorname{argmax}_{q} \beta v(e, q, w)-k(q) .
$$

Note that $q^{\mathrm{B}}(e)$ is positive because the model assumptions, in particular $\beta>0$, ensure that there is an inner solution to this problem.

We thus have two benchmarks. While $q^{\mathrm{A}}$ describes the contribution determined by the authority, $q^{\mathrm{B}}$ stands for the contribution if the bureaucrat had full power. Later, we will derive the actual contribution $q$ as a function of these benchmarks.

If the contribution imposed by the authority $q^{\mathrm{A}}$ is below the unfettered bureaucrat's contribution $q^{\mathrm{B}}$, there is no point in ever appealing to the authority. In the following, we thus restrict attention to the case where $q^{\mathrm{A}}(e)>q^{\mathrm{B}}(e)$.

The market setting provides an example for a situation in which the contributions by the authority are larger at all effort levels. In this setting, competition pushes contributions from $q^{\mathrm{B}}(e)$ up to $q^{\mathrm{A}}(e) .^{5}$

\footnotetext{
${ }^{5}$ Formally, one can show that the derivative of the bureaucrat's utility at $q^{\mathrm{A}}(e)$ is
} 


\subsection{Elasticity of contributions}

Later, it will be important how the two benchmark contributions, $q^{\mathrm{A}}$ and $q^{\mathrm{B}}$, respond to changes in effort. The following definition helps us to describe the relative effect of effort on $q^{\mathrm{A}}$ and $q^{\mathrm{B}}$.

Definition 1 (Elasticity). The contribution $q^{i}(e)$ is more elastic in effort $e$ than $q^{j}(e)$ if

$$
\frac{d q^{i}(e)}{d e} \frac{e}{q^{i}(e)}>\frac{d q^{j}(e)}{d e} \frac{e}{q^{j}(e)} \text { for all } e>0 .
$$

The two relevant cases for our analysis are that contributions by the authority are more elastic than those by the unfettered bureaucrat and vice versa. ${ }^{6}$ In most applications, the contribution imposed by the authority is probably more elastic than that of the bureaucrat. The President is likely to respond more favorably to an increase in effort by the department than the Dean. Similarly, the leading official from the international organization is more eager to increase contributions than the local representative who diverts them. In the market setting, it suffices that effort and contributions are substitutes. Then, the contribution by an unfettered bureaucrat $q^{\mathrm{B}}(e)$ falls in effort while effort increases the value and hence the contribution $q^{\mathrm{A}}(e)$ that can be obtained on the market.

Of course, one could also imagine that the Dean or local representative rewards effort more than the vice chancellor or the local representative. Our results deal with both cases. As a leading example, we refer to the case where the contributions by the authority are more elastic.

negative. Since the bureaucrat's utility is concave this implies that $q^{\mathrm{B}}(e)<q^{\mathrm{A}}(e)$.

${ }^{6}$ In both cases the definition is well-defined because we have restricted the analysis to the case $q^{\mathrm{A}}(e)>q^{\mathrm{B}}(e)$ and because $q^{\mathrm{B}}(e)>0$. 


\section{Behavior in equilibrium}

As a solution concept, we employ the subgame-perfect equilibrium and solve the game in four steps using backward induction. First, we determine whether the manager of the non-profit unit appeals to the authority or not given the exerted effort and the contribution offered by the bureaucrat. Second, we analyze the bureaucrat's decision as to how much of the contribution to pass on to the non-profit unit. Then, we examine the behavior of the worker. Finally, we deal with the adjustment of the wage.

\subsection{Decision of non-profit manager}

The manager has to decide whether to accept the proposal $q$ by the bureaucrat or whether to lobby for higher contributions $q^{\mathrm{A}}$. The manager prefers larger contributions and thus has to weigh the prospect of attaining $q^{\mathrm{A}}$ against the offer $q$ by the bureaucrat. Given our assumptions about the exponential arrival of opportunities to overturn $q$, the certainty equivalent from the manager's perspective to obtain $q^{\mathrm{A}}$ amounts to:

$$
\int_{0}^{\infty} e^{-r \tau} q^{\mathrm{A}}(e) \quad e^{-\theta \tau} \theta d \tau=\frac{\theta}{r+\theta}=\delta(\theta) q^{\mathrm{A}}(e), \text { with } \delta(\theta):=\frac{\theta}{r+\theta} .
$$

The non-profit manager thus accepts any contribution $q$ that is equal to $\delta q^{\mathrm{A}}(e)$ or larger. Otherwise he refuses.

\subsection{Contribution by bureaucrat}

The bureaucrat foresees the decision of the non-profit manager. She thus knows that she can avoid appeal by offering a contribution $q \geq \delta q^{\mathrm{A}}(e)$. 
Indeed, it is optimal for her to offer at least $\delta q^{\mathrm{A}}(e)$ and prevent appeal (see Lemma 1 in the appendix). The intuition is that the bureaucrat has to pass on an even larger contribution after the successful appeal.

Accordingly, the bureaucrat will offer a contribution in equilibrium that maximizes her utility while ensuring immediate agreement: $q \geq \delta q^{\mathrm{A}}(e)$. If her contribution while being unfettered, $q^{\mathrm{B}}(e)$, leads to an immediate settlement, then she chooses this contribution. If contributing $q^{\mathrm{B}}(e)$ is not enough to prevent appeal $\left(q^{\mathrm{B}}(e)<\delta q^{\mathrm{A}}(e)\right)$, then she settles for the smallest possible contribution that prevents an appeal $\left.\delta q^{\mathrm{A}}(e)\right) .{ }^{7}$ So in this case, the constraint binds. Overall, the actual contribution by the bureaucrat $q$ is $q^{\mathrm{B}}$ if $q^{\mathrm{B}} \geq \delta q^{\mathrm{A}}$ and $\delta q^{\mathrm{A}}$ else. More succinctly:

$$
q(e):=\max \left\{\delta q^{\mathrm{A}}(e), q^{\mathrm{B}}(e)\right\}
$$

Notice that the contribution $q(e)$ depends on the worker's effort. The worker's effort decision may thus influence whether the bureaucrat can freely choose the level of contributions or is restricted. There are, however, two important exceptions. First, the opportunity to overturn the offer by the bureaucrat may never arise $(\theta=0)$. Then, the appeal has no value and the bureaucrat has dictatorial power. Since the bureaucrat is unfettered, contributions are $q(e)=q^{\mathrm{B}}(e)$ for any effort level. Second, the outside opportunity may arise immediately $(\theta=\infty)$. Then, the bureaucrat has no power and the authority determines contributions, so that $q(e)=\delta q^{\mathrm{A}}(e)$ for any effort level. At intermediary power levels, the bureaucrat may be limited for some

\footnotetext{
${ }^{7}$ Recall that the bureaucrat's utility is concave, so that it is falling at $q$ for $q^{\mathrm{B}}<q$. Because $q^{\mathrm{B}}<\delta q^{\mathrm{A}}$, the utility is also falling in contributions for $q$ such that $q \geq \delta q^{\mathrm{A}}$.
} 
effort $e$ while she is unfettered for another effort level $e^{\prime}$ :

$$
\delta(\theta) q^{\mathrm{A}}(e) \geq q^{\mathrm{B}}(e) \text { and } \delta(\theta) q^{\mathrm{A}}\left(e^{\prime}\right) \leq q^{\mathrm{B}}\left(e^{\prime}\right) \text { for some } e, e^{\prime} .
$$

Given such regime shifts, it is reasonable to ask for what effort levels the threat to appeal restricts the bureaucrat. The answer is given in the next proposition.

Proposition 1 (Effort and the threat to appeal). Consider an arrival rate $\theta$ such that (3) holds. If the contribution imposed by the authority $q^{A}$ is more elastic than the contribution by the unfettered bureaucrat $q^{B}$, then there is a unique effort level $\tilde{e}$ such that the threat to appeal binds for larger effort:

$$
q^{B}(e)>\delta q^{A}(e) \text { for } e<\tilde{e} \text { and } q^{B}(e)<\delta q^{A}(e) \text { for } e>\tilde{e} .
$$

If $q^{B}$ is more elastic than $q^{A}(e)$, the converse holds. ${ }^{8}$

Proof. We focus on the case that $q^{\mathrm{A}}$ is more elastic (the case that $q^{\mathrm{B}}$ is more elastic can be proven completely analogously). Note that the contribution by an unfettered bureaucrat as well as those imposed by the authority are continuous in $e$. Because $q^{\mathrm{B}}(e) \geq \delta q^{\mathrm{A}}(e)$ for some $e$ and $q^{\mathrm{B}}\left(e^{\prime}\right) \leq \delta q^{\mathrm{A}}\left(e^{\prime}\right)$ for some $e^{\prime}$, there is some $\tilde{e}$ such that $q^{\mathrm{B}}(\tilde{e})=\delta q^{\mathrm{A}}(\tilde{e})$. Since $q^{\mathrm{A}}(e)$ is more elastic, $\frac{q^{\mathrm{B}}(e)}{q^{\mathrm{A}}(e)} \frac{d}{d e} q^{\mathrm{A}}(e)>\frac{d}{d e} q^{\mathrm{B}}(e)$. Evaluated at any $\tilde{e}$, this becomes $\delta \frac{d}{d e} q^{\mathrm{A}}(\tilde{e})>$ $\frac{d}{d e} q^{\mathrm{B}}(\tilde{e})$. So at any intersection of $\delta q^{\mathrm{A}}$ and $q^{\mathrm{B}}$, the derivative of the former in effort is larger than that of the latter: $\frac{d}{d e} \delta q^{\mathrm{A}}(\tilde{e})>\frac{d}{d e} q^{\mathrm{B}}(\tilde{e})$. This implies

\footnotetext{
${ }^{8}$ That means, there is a unique effort $\tilde{e}$ such that

$$
q^{\mathrm{B}}(e)<\delta q^{\mathrm{A}}(e) \text { for } e<\tilde{e} \text { and } q^{\mathrm{B}}(e)>\delta q^{\mathrm{A}}(e) \text { for } e>\tilde{e}
$$
}


for the neighborhood of $\tilde{e}$ that $\delta q^{\mathrm{A}}(e)<q^{\mathrm{B}}(e)$ for $e<\tilde{e}$ and $\delta q^{\mathrm{A}}(e)>q^{\mathrm{B}}(e)$ for $e>\tilde{e}$. To show that these inequalities hold generally and that there is only one intersection, suppose there would be an effort $\hat{e} \neq \tilde{e}$ such that $q^{\mathrm{B}}(\hat{e})=\delta q^{\mathrm{A}}(\hat{e})$. Then, we get $\frac{d}{d e} \delta q^{\mathrm{A}}(\hat{e})>\frac{d}{d e} q^{\mathrm{B}}(\hat{e})$. This implies that at both intersections $\delta q^{\mathrm{A}}(e)$ crosses $q^{\mathrm{B}}(e)$ from below, and contradicts that $\delta q^{\mathrm{A}}(e)$ and $q^{\mathrm{B}}(e)$ are continuously differentiable functions of effort. Consequently, we cannot maintain that there is more than one effort level such that $q^{\mathrm{B}}(e)=$ $\delta q^{\mathrm{A}}(e)$

The proposition is based on the idea that the non-profit unit appeals and thus restricts the bureaucrat whenever there is enough to gain from an appeal. Consider the case that the contributions imposed by the authority are more elastic. Then, the the contributions of the authority $q^{\mathrm{A}}$ have a larger growth rate than the contributions of the unfettered bureaucrat $q^{\mathrm{B}}$. Since the value of appeal $\delta q^{A}(e)$ is proportional to the contributions by the authority, it grows more than the contribution of the unfettered bureaucrat $q^{\mathrm{B}}$. Initially, the bureaucrat is unrestricted and chooses her preferred contribution $q=q^{\mathrm{B}}$. Eventually, the value $\delta q^{\mathrm{A}}$ exceeds the contribution $q^{\mathrm{B}}$, the threat to appeal starts to bind, and the bureaucrat provides just enough contributions $q$ to prevent appeal (see Figure 1). Overall, low efforts lead to $q^{\mathrm{B}}$ and high efforts to $\delta q^{\mathrm{A}}$. Using an analogous argument, low efforts lead to $\delta q^{\mathrm{A}}$ and high efforts to $q^{\mathrm{B}}$ if $q^{\mathrm{B}}$ is more elastic. In both cases, low effort by the worker yields contributions of a different nature than high effort. In the next section, we examine how the effect of effort on contributions impinges on the worker's effort choice. 


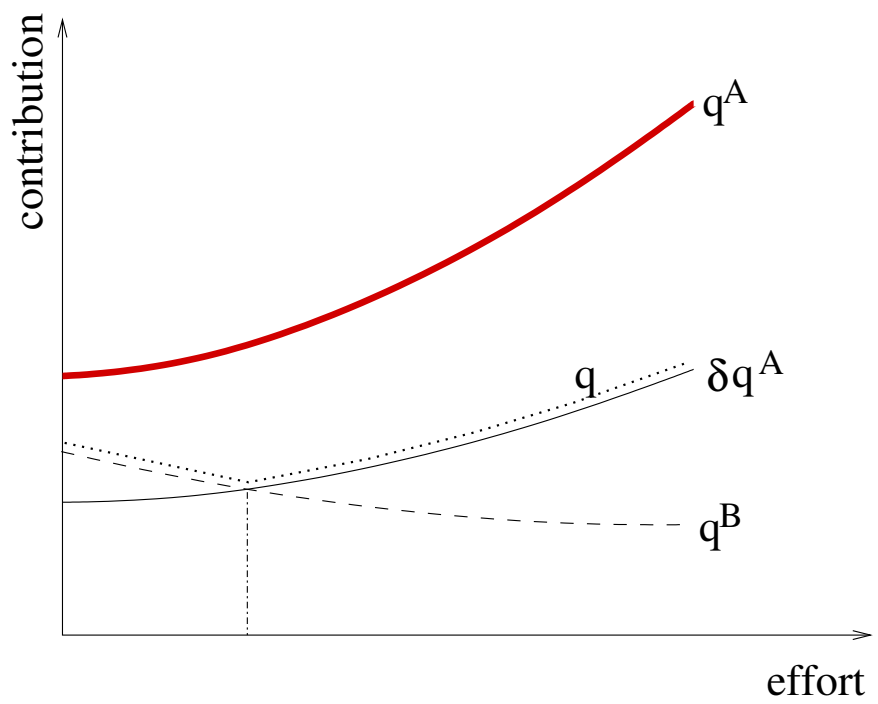

Figure 1: Example of a shift in the nature of contributions q: For low effort, the bureaucrat is unfettered, $q=q^{\mathrm{B}}$; for high effort, she contributes just enough to avert appeal, $q=\delta q^{\mathrm{A}}$. 


\subsection{Effort by worker}

Since the worker cares about the value of the product, his utility depends on the level of contributions. It is useful to distinguish between the worker's utility if contributions are determined by the threat of appeal $u^{\mathrm{A}}$ and if contributions come from an unfettered bureaucrat $u^{\mathrm{B}}$. Formally,

$$
\begin{aligned}
u_{\theta}^{\mathrm{A}}(e, w) & :=\alpha v\left(e, \delta(\theta) q^{\mathrm{A}}(e), w\right)-c(e) \text { and } \\
u^{\mathrm{B}}(e, w) & :=\alpha v\left(e, q^{\mathrm{B}}(e), w\right)-c(e) .
\end{aligned}
$$

Each of these utility functions is maximized by some effort choice. ${ }^{9}$ Denote the (smallest) maximizers of the two problems by $e_{\theta}^{\mathrm{A}}$ and $e^{\mathrm{B}}$.

The actual utility of the agent amounts to $u_{\theta}^{\mathrm{A}}$ for those effort levels $e$ for which contributions are determined by the threat to appeal $\left(q(e)=\delta q^{\mathrm{A}}(e)\right)$. Conversely, the utility is described by $u^{\mathrm{B}}$ given that contributions are from an unfettered bureaucrat $\left(q(e)=q^{\mathrm{B}}(e)\right)$. From the previous section, we know that the actual contribution is always the maximum of the two types of contributions (see Equation (2)). Accordingly, we get:

$$
u_{\theta}(e, w)=\left\{\begin{array}{cl}
u_{\theta}^{\mathrm{A}}(e, w) & \text { if } \delta(\theta) q^{\mathrm{A}}(e)>q^{\mathrm{B}}(e) \\
u_{\theta}^{\mathrm{A}}(e, w)=u^{\mathrm{B}}(e, w) & \text { if } \delta(\theta) q^{\mathrm{A}}(e)=q^{\mathrm{B}}(e) \\
u^{\mathrm{B}}(e, w) & \text { if } \delta(\theta) q^{\mathrm{A}}(e)<q^{\mathrm{B}}(e) .
\end{array}\right.
$$

Observe that $u_{\theta}^{\mathrm{A}}$ and $u^{\mathrm{B}}$ only differ with respect to the type of contribution. Since they are also monotonic in contributions, the worker's utility can be succinctly written as:

$$
u_{\theta}(e, w)=\max \left\{u_{\theta}^{\mathrm{A}}(e, w), u^{\mathrm{B}}(e, w)\right\} .
$$

\footnotetext{
${ }^{9}$ Since $\delta(\theta) q^{\mathrm{A}}$ as well as $q^{\mathrm{B}}$ are continuous functions of $e$ and $e$ comes from a compact interval, the maximizer exists.
} 
This representation reveals that the worker's utility is continuous in effort and attains a maximum at $e_{\theta}^{\mathrm{A}}$ or at $e^{\mathrm{B}}$ (for a formal proof see Lemma 2 in the appendix).

Consider an intermediary power level and take the example of contributions imposed by the authority being more elastic than those chosen by an unfettered bureaucrat. Then, the bureaucrat is unfettered for low effort levels and restricted for high effort by Proposition 1. So, for low efforts the worker's utility is described by $u^{\mathrm{B}}(e, w)$ and for high efforts by $u_{\theta}^{\mathrm{A}}(e, w)$. The worker can now either exert high effort and force the bureaucrat to supply $\delta(\theta) q^{\mathrm{A}}$ or exert little effort and obtain $q^{\mathrm{B}}$. Which of these options is more attractive depends on the power of the non-profit unit. The larger this power, the more attractive becomes the option to exert high effort. It seems intuitive that there is some critical power level such that the worker is exactly indifferent between the two options. The following proposition asserts that such a critical power exists.

Proposition 2 (Arrival rate and the threat to appeal). Holding the wage $w$ constant, there is a critical arrival rate $\theta^{*}$ for which the worker is indifferent between the effort that maximizes his utility when the bureaucrat is unfettered and the respective effort when the bureaucrat is restricted:

$$
u_{\theta^{*}}^{A}\left(e_{\theta^{*}}^{A}, w\right)=u^{B}\left(e^{B}, w\right)
$$

For a higher arrival rate $\left(\theta>\theta^{*}\right)$, the worker's effort choice restricts the bureaucrat and for a lower arrival rate $\left(\theta<\theta^{*}\right)$, the worker's effort choice leaves the bureaucrat unfettered.

Proof. The proof is based on the intermediate value theorem. First, note 
that $u_{\theta}^{\mathrm{A}}\left(e_{\theta}^{\mathrm{A}}, w\right)$ is a continuous increasing function in $\theta$ by Lemma 5 . Next, we examine the relationship between $u_{\theta}^{\mathrm{A}}\left(e_{\theta}^{\mathrm{A}}, w\right)$ and $u^{\mathrm{B}}(e, w)$ for two values of $\theta$. For $\theta=0$, we get $u_{\theta}^{\mathrm{A}}(e, w) \leq u^{\mathrm{B}}(e, w)$ by Lemma 4 . This implies that $u_{\theta}^{\mathrm{A}}\left(e_{\theta}^{\mathrm{A}}, w\right) \leq u^{\mathrm{B}}\left(e_{\theta}^{\mathrm{A}}, w\right) \leq u^{\mathrm{B}}\left(e^{\mathrm{B}}, w\right)$. For large $\theta$, we get $u_{\theta}^{\mathrm{A}}(e, w) \geq u^{\mathrm{B}}(e, w)$ by Lemma 3 . This implies that $u_{\theta}^{\mathrm{A}}\left(e_{\theta}^{\mathrm{A}}, w\right) \geq u^{\mathrm{A}}\left(e^{\mathrm{B}}, w\right) \geq u^{\mathrm{B}}\left(e^{\mathrm{B}}, w\right)$. Since $u_{\theta}^{\mathrm{A}}\left(e_{\theta}^{\mathrm{A}}, w\right)$ is continuous and increasing in $\theta$, there is a unique $\theta^{*}$ such that $u_{\theta^{*}}^{\mathrm{A}}\left(e_{\theta^{*}}^{\mathrm{A}}, w\right)=u^{\mathrm{B}}\left(e^{\mathrm{B}}, w\right)$.

Proposition 1 has introduced the possibility that the worker affects the nature of contributions by choosing either high or low effort. Proposition 2 shows that this regime shift actually occurs. If the non-profit unit's power attains the critical value, the worker's decision changes and with it the type of contribution. The next result informs us about the effort choices by the worker associated with the regime shift.

Theorem 1 (Discontinuity of effort). Suppose that the wage $w$ is constant. If the contribution imposed by the authority $q^{A}(e)$ is more elastic than the contribution by an unfettered bureaucrat $q^{B}(e)$, a marginal decrease of the arrival rate beyond a critical arrival rate leads to a discontinuous decrease in effort. ${ }^{10}$

If $q^{B}(e)$ is more elastic than $q^{A}(e)$, the marginal decrease leads to a discontinuous increase in effort.

Proof. Again, the proof focuses on the case that contributions imposed by the authority are more elastic than those by an unfettered bureaucrat. Proving

\footnotetext{
${ }^{10}$ In formulas, let $e_{\theta}$ be the optimal effort choice of the worker given $\theta$. Then, there is an $\epsilon>0$ for arbitrary small $\delta>0$ and arrival rates $\theta_{1}, \theta_{2}$ with $\theta^{*}-\delta<\theta_{1}<\theta^{*}<\theta_{2}<\theta^{*}+\delta$ such that $e_{\theta_{2}}-e_{\theta_{1}}>\epsilon$.
} 
the other case is completely analogous. By Lemma 2, the only candidates for a maximizer are $e_{\theta}^{\mathrm{A}}$ and $e^{\mathrm{B}}$. By Proposition 2, there is a critical arrival rate $\theta^{*}$ with $u^{\mathrm{B}}\left(e^{\mathrm{B}}, w\right)=u_{\theta^{*}}^{\mathrm{A}}\left(e_{\theta^{*}}^{\mathrm{A}}, w\right)$. This in turn means that equation (3) is met. To see this, set $e=e^{\mathrm{B}}, e^{\prime}=e_{\theta^{*}}^{\mathrm{A}}$ and observe that $q^{\mathrm{B}}(e) \geq \delta(\theta) q^{\mathrm{A}}(e)$ and

$$
q^{\mathrm{B}}\left(e^{\prime}\right) \leq \delta(\theta) q^{\mathrm{A}}\left(e^{\prime}\right)
$$

Using that $q^{\mathrm{A}}$ is more elastic than $q^{\mathrm{B}}$ and applying Proposition 1 yields a unique $\tilde{e}$ such that $q^{\mathrm{B}}>\delta q^{\mathrm{A}}$ for all $e<\tilde{e}$. Since $u_{\theta}^{\mathrm{A}}(e, w)$ and $u^{\mathrm{B}}(e, w)$ only differ in terms of contributions, we get $u^{\mathrm{B}}(e, w)>u_{\theta^{*}}^{\mathrm{A}}(e, w)$ for all $e<\tilde{e}$. With inequality (4), it follows that $e_{\theta^{*}}^{\mathrm{A}} \geq \tilde{e}$. Completely analogously, we get $e^{\mathrm{B}} \leq \tilde{e}$. In the final step of the proof, we want to rule out that $e^{\mathrm{B}}=e_{\theta^{*}}^{\mathrm{A}}=\tilde{e}$. Suppose this would be the case. Then, $u^{\mathrm{B}}\left(e^{\mathrm{B}}, w\right)=u_{\theta^{*}}^{\mathrm{A}}\left(e_{\theta^{*}}^{\mathrm{A}}, w\right)$ together with the monotonicity of $v$ in $q$ implies that

$$
\delta\left(\theta^{*}\right) q^{\mathrm{A}}\left(e_{\theta^{*}}^{\mathrm{A}}\right)=q^{\mathrm{B}}\left(e^{\mathrm{B}}\right)=: \tilde{q} .
$$

Recall that $e_{\theta}^{\mathrm{A}}$ and $e^{\mathrm{B}}$ are inner solutions, so that the derivative of $u^{\mathrm{B}}$ and $u_{\theta^{*}}^{\mathrm{A}}$ with respect to $e$ and evaluated at $\tilde{e}$ and $\tilde{q}$ have to be zero and thus identical. The derivatives of $u_{\theta}^{\mathrm{A}}$ is $\frac{\partial u}{\partial e}+\frac{\partial u}{\partial q} \cdot \frac{d\left(\delta\left(\theta^{*}\right) q^{\mathrm{A}}\right)}{d e}$ and that of $u^{\mathrm{B}}$ is $\frac{\partial u}{\partial e}+\frac{\partial u}{\partial q} \cdot \frac{d q^{\mathrm{B}}}{d e}$. For the two terms to be identical, it must hold that $\frac{d\left(\delta\left(\theta^{*}\right) q^{\mathrm{A}}\right)}{d e}=\frac{d q^{\mathrm{B}}}{d e}$ at $\tilde{e}$. Using equation (5), the equality becomes $\frac{q^{\mathrm{B}}(\tilde{e})}{q^{\mathrm{A}}(\tilde{e})} \frac{d q^{\mathrm{A}}}{d e}=\frac{d q^{\mathrm{B}}}{d e}$. This, however, contradicts the assumption that $q^{\mathrm{A}}$ is more elastic than $q^{\mathrm{B}}$. Consequently, the assumption $e^{\mathrm{B}}=e_{\theta^{*}}^{\mathrm{A}}$ must be wrong. Since $e_{\theta^{*}}^{\mathrm{A}} \geq \tilde{e} \geq e^{\mathrm{B}}$, this implies: $e_{\theta^{*}}^{\mathrm{A}}>e^{\mathrm{B}}$.

The basic intuition for the proof is simple. Since the worker cares about contributions and the two types of contributions respond differently to effort, 
the marginal effect of effort on the worker's utility differs and the maximizing effort choices lie apart. Consequently, the shift in restriction caused by a change in the arrival rate (see Proposition 2) translates into discrete change of effort.

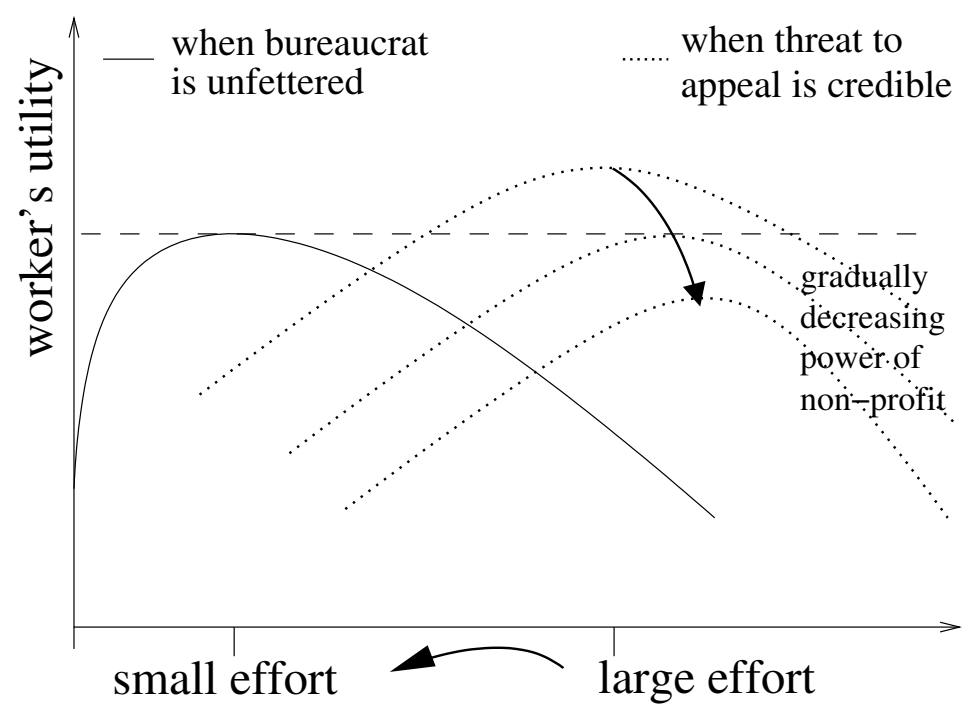

Figure 2: Drop in effort provision when non-profit unit loses power

The core message of the theorem is that the worker eventually responds abruptly to seemingly irrelevant changes in the bureaucratic context. Consider the case of contributions imposed by the authority being more elastic than those by the unfettered bureaucrat. Then, a sequence of small alterations that prompt seemingly insignificant reductions in the bargaining stance of the non-profit unit will at some point drastically erode motivation. Notice that the alterations may initially even have a positive effect on effort (see Figure 3.3). 


\subsection{Wage adjustments}

Near the critical arrival rate, an increase of this rate augments the worker's utility. The manager of the non-profit unit can benefit from the worker's gains without risking losing the worker by cutting wages. In other words, the wage $w$ will adjust to changes in the arrival rate $\theta$. How do wages adjust and will changes in the arrival rate still lead to a regime change? The answer is given by the following theorem.

Theorem 2 (Regime shift with wage adjustments). A small decrease of the arrival rate at the critical point $\theta^{*}$ does not affect the wage and leads to an effort level that leaves the bureaucrat unfettered. Conversely, an increase in the arrival rate implies a lower wage and the respective effort restricts the bureaucrat.

Proof. In equilibrium, the manager pushes the wage to the smallest possible value that is still acceptable for the worker. Denoting the equilibrium values for effort, contribution and wage by $\left(e_{\theta^{*}}, q^{*}, w^{*}\right)$ if the arrival rate is $\theta^{*}$ and by $\left(e_{\tilde{\theta}}, \tilde{q}, \tilde{w}\right)$ if it is $\tilde{\theta}$, we get:

$$
u\left(e_{\theta^{*}}, q^{*}, w^{*}\right)=u\left(e_{\tilde{\theta}}, \tilde{q}, \tilde{w}\right)=\underline{u}
$$

where $\underline{u}$ was the worker's utility if he rejects the offered wage. Based on this equation, we first study the effect of an decrease of $\theta$ and then that of an increase.

Case 1: $\tilde{\theta}<\theta^{*}$. Suppose the wage increases: $\tilde{w}>w^{*}$. Then, the worker can exert $e^{\mathrm{B}}$ and as the utility increases in the wage, he obtains at least $u^{\mathrm{B}}\left(e^{\mathrm{B}}, \tilde{w}\right)>u^{\mathrm{B}}\left(e^{\mathrm{B}}, w^{*}\right)=\underline{u}$. This violates equation (6). Thus, $w^{*} \geq \tilde{w}$. 
Suppose the wage decreases: $\tilde{w}<w^{*}$. Then, $u_{\tilde{\theta}}^{\mathrm{A}}\left(\tilde{e}^{\mathrm{A}}, \tilde{w}\right)<\underline{u}$ because $u_{\theta}^{\mathrm{A}}$ falls in the arrival rate (see Lemma 5) and the wage. Likewise, $u^{\mathrm{B}}$ falls in the wage so that $u^{\mathrm{B}}\left(\tilde{e}^{\mathrm{B}}, \tilde{w}\right)<\underline{u}$. Irrespective of whether the bureaucrat is restricted or not, the worker will have less than $\underline{u}$, which contradicts once more equation (6). Overall, $\tilde{w}=w$. Finally, we examine the effort choice under $\tilde{\theta}$. Since the wage stays constant $\left(w^{*}=\tilde{w}\right)$ and the arrival rate has dropped, $u_{\tilde{\theta}}^{\mathrm{A}}\left(\tilde{e}^{\mathrm{A}}, \tilde{w}\right)<u_{\theta^{*}}^{\mathrm{A}}\left(e_{\theta^{*}}^{\mathrm{A}}, w^{*}\right)=\underline{u}$. On the other hand, $u^{\mathrm{B}}\left(e^{\mathrm{B}}, \tilde{w}\right)=$ $u^{\mathrm{B}}\left(e^{\mathrm{B}}, w^{*}\right)=\underline{u}$. So, the worker's utility is maximized at $e^{\mathrm{B}}$ in the case $\tilde{\theta}<\theta^{*}$.

Case 2: $\theta^{*}<\tilde{\theta}$. Suppose $\tilde{w} \geq w^{*}$. Then, $u_{\theta^{*}}^{\mathrm{A}}\left(e_{\theta^{*}}^{\mathrm{A}}, \tilde{w}\right) \geq u_{\theta^{*}}^{\mathrm{A}}\left(e_{\theta^{*}}^{\mathrm{A}}, w^{*}\right)$. Moreover, $u_{\tilde{\theta}}^{\mathrm{A}}\left(e_{\theta^{*}}^{\mathrm{A}}, \tilde{w}\right)>u_{\theta^{*}}^{\mathrm{A}}\left(e_{\theta^{*}}^{\mathrm{A}}, \tilde{w}\right)$ because $\delta(\tilde{\theta}) q^{\mathrm{A}}>\delta\left(\theta^{*}\right) q^{\mathrm{A}}$. Overall, $u_{\tilde{\theta}}^{\mathrm{A}}\left(e_{\theta^{*}}^{\mathrm{A}}, \tilde{w}\right)>u_{\theta^{*}}^{\mathrm{A}}\left(e_{\theta^{*}}^{\mathrm{A}}, w^{*}\right)=\underline{u}$. Consequently, $e_{\theta}^{\mathrm{A}}$ yields the worker a utility strictly above $\underline{u}$. This, however, contradicts (6). Thus, $\tilde{w}<w^{*}$. Next, we examine the effort choice. Suppose that the effort choice leaves the bureaucrat unrestricted. Then, the worker obtains $u^{\mathrm{B}}\left(\tilde{e}^{\mathrm{B}}, \tilde{w}\right)<u^{\mathrm{B}}\left(e^{\mathrm{B}}, w^{*}\right)=\bar{u}$ because of $\tilde{w}<w^{*}$. Once more, we have a contradiction to (6). This implies that the worker chooses effort $e_{\tilde{\theta}}^{A}$.

The theorem confirms that the shift from a restricted to an unrestricted bureaucrat, which is due to a lower arrival rate, is not affected by wage adjustments. The basic idea is that while wages influence the absolute level of the worker's utility, they do not alter the relationship between the utility when the bureaucrat is unrestricted and when she is restricted. Increasing the arrival rate renders restricting the bureaucrat more attractive in comparison to leaving her unrestricted.

For the message of Theorem 1 to fully apply when wages adjust, the worker's effort choice associated with the shift from a restricted to an un- 
restricted bureaucrat must be distinctly different. Since wage adjustments are continuous in the arrival rate, the marginal effects of effort on worker's utility are close to those before the wage adjustment. The difference between the marginal effect of effort on the utility when the bureaucrat is restricted and unfettered remains. Therefore even if wages adjust, the earlier intuition carries over: the utility maximizing efforts given a restricted and an unrestricted bureaucrat lie apart. Adapting the proof of Theorem 1, thus gives us the following corollary.

Corollary 1 (Discontinuous effort with wage adjustments). Suppose that the contribution imposed by the authority $q^{A}(e)$ is more elastic than the contribution by the unfettered bureaucrat $q^{B}(e)$. Then, a rise in the arrival rate leads to a discontinuous increase in effort. If $q^{B}(e)$ is more elastic than $q^{A}(e)$, a rise in the arrival rate leads to a discontinuous fall in effort.

The central message of this section is that our main findings are not affected when the manager adjusts the wage. Small changes in the bureaucratic context of the non-profit unit eventually lead to abrupt changes in worker's behavior. The direction of these changes depends on the elasticity of the different types of contribution in the same way as before.

\section{Conclusion}

When do workers who care about the value of their work donate labor? It has been pointed out by various authors (see e.g. Francois, 2000 or Glaeser and Shleifer, 2001) that the inner structure of the organization matters. Here, we extend this observation to the context of the organization. We consider 
a simple but relevant setting in which an bureaucrat cares to some (possibly low) degree about production and contributes to it while her choice is limited by the alternatives available to the organization. This setting covers bureaucratic environments as well as markets with friction.

Our model describes an environment in which important variables such as the effort of the workers, contributions of the bureaucrat and the value of the product cannot be fully verified by a third party. This incompleteness is crucial for our results because neither the structure of an organization nor its context matters for incentives if inputs and outputs can be completely determined in a contract or by a formal set of rules. The same assumption is often evoked in the context of non-profit organizations, ${ }^{11}$ in the incomplete contract literature, ${ }^{12}$ and in principal-agent models. ${ }^{13}$ The problem of verifying inputs and outputs is also at the heart of James Q. Wilson's monograph on governmental agencies (1989); using his words, the institution described in our model is a 'coping organization.'

Our central finding is the abrupt change in donated labor as a response to a small change in the power relationship between non-profit unit and bureaucrat (Theorem 1). Observe that not all marginal changes in the power of the non-profit unit trigger strong effects on donated labor. These effects occur only when power falls below a critical threshold. The university admin-

\footnotetext{
${ }^{11}$ See Henry B. Hansmann (1980), Easley and O’Hara (1983), Francois (2000) Glaeser and Shleifer (2001)

${ }^{12}$ See Benjamin Klein, Robert G. Crawford and Armen A. Alchian (1978), Holmström (1999), Grout (1984), Grossman and Hart (1986), or Hart (1995).

${ }^{13}$ See Holmström (1979) and (1982), Steven Shavell (1979) Holmström and Milgrom (1991) and (1994).
} 
istration, for example, may implement several changes that transfer power from the departmental to the faculty level without any dramatic effects on donated labor. The response to these changes is stable until a critical point is reached and donated labor abruptly changes. The dramatic response to seemingly unimportant changes is reminiscent of the butterfly effect known from physics, which states that a small alteration in initial conditions of a dynamic system may lead to very different results (for a description of this idea and its history see Robert C. Hilborn 2004). In contrast, our finding rests on a comparative statics and not a dynamic analysis. A perhaps more important difference is that we describe a social and not a physical phenomenon. The driving force behind the discontinuity finding is that bureaucrat and authority 'reward' donated labor differently. As long as this is the case, the marginal effect of workers' effort differ between the different regimes and so will their optimal choices. For the argument, it does not matter who responds more favorable to effort, bureaucrat or authority.

If we want to determine the direction of the effect of the non-profit unit's power on donated labor, however, it becomes important whether the bureaucrat or the authority is more responsive to changes in donated labor. Suppose a policy maker is interested in providing ideal conditions for donated labor and can influence the power of the non-profit unit in relation to the bureaucrat (which could also be interpreted as the degree of decentralization). How should this policy maker allocate power? The answer depends on whether the authority or the bureaucrat respond more favorably to effort. In many applications, it could be argued that the authority 'rewards' effort while the bureaucrat 'punishes' it. Under reasonable assumptions, such behavior also 
occurs in our three examples.

Take the example of the NGO and the corrupt representative. Assume that the corrupt representative is not genuinely interested in the work by the NGO but her promotional prospects are affected if the project fails (i.e. the project's value falls below a certain threshold). If more labor is donated, then the project becomes more successful and the representative can divert more contributions without jeopardizing the project's 'success.' So, the representative reduces contributions when effort increases. On the other hand, the international organization might fight corruption more intensely, the higher the effort of the NGO. Then, contributions imposed by this organization increase with larger effort.

In the other two examples, it suffices to assume that effort and contributions are substitutes. Then, the marginal value of contributions falls when effort rises and even a bureaucrat who genuinely cares about the product of the non-profit unit, e.g. the Dean in the university example, will cut contributions as a response to larger effort. On the other hand, the authority, e.g. the President, may be concerned about maximizing the department's value (under the constraint that the bureaucrat does not suffer from contributing). Since more effort increases this value and hence the bureaucrat's utility, the authority can and will demand higher contributions from the bureaucrat if effort increases. Applied to the market example, substitutability implies that the buyer's contributions drop with rising effort whereas the market value 
and thus contributions of competing buyers increase. ${ }^{14}$

If contributions imposed by the authority are more elastic in effort than those of the bureaucrat, e.g. because the authority 'rewards' effort and the bureaucrat 'punishes' it, donated labor is maximized by allocating more power to the non-profit unit. A slow reduction of this power from an initially high level, triggers the sudden breakdown of a formerly healthy work culture because employees realize that their efforts no longer 'make a difference.' In line with this reasoning, the collapse of morale among employees at the Federal Emergency Management Agency (FEMA) and the ensuing ill preparation for hurricane Katrina has been attributed to a slow erosion of the standing of FEMA in relation to its parent institution, the Department of Homeland Security, and the related diversion of funds by this instituion. ${ }^{15}$

Our finding highlights that the context in which an organization operates matters for donated labor. It has been argued by Avinash Dixit (2002) that the attempt to provide stronger incentives within organizations in the public sector may fail due to the difficulties in describing inputs and outputs of the products typically produced, e.g. security, health, etc. But public sector reform also concerns the context of organizations. For example, the Blair government in the UK pushed for quantifiable targets and holding organizations in the public sector (such as the NHS) accountable for meeting these targets. Apart from the well-known difficulty in formulating quantifiable tar-

\footnotetext{
${ }^{14}$ If effort and contributions are complements, both the first buyer and the market reward more effort. In this case, it depends on the degree of complementarity and thus on the specific functional form whose contributions are more elastic.

${ }^{15}$ See the article "FEMA's decline: an agency's slow slide from grace" by Justin Rood in the Government Executive Magazine, vol. 37 (17), 2005.
} 
gets that do not fall foul of the multi-tasking problems described by Bengt Holmström and Paul Milgrom (1991), ${ }^{16}$ this article points to another potential pitfall with this approach. If holding organizations responsible weakens their bargaining positions in negotiations, rents to these organizations are squeezed. While this seems attractive because it reduces costs, it also has an impact on donated labor: it may reduce marginal incentives to donate labor because it becomes more difficult for workers to make a difference when their organization is weak.

\section{References}

Bénabou, Roland and Jean Tirole, "Intrinsic and Extrinsic Motivation," Review of Economic Studies, 2003, 70, 489-520.

Benabou, Roland and Jean Tirole, "Incentives and Prosocial Behavior," American Economic Review, December 2006, 96 (5), 1652-1678.

Besley, Timothy and Maitreesh Ghatak, "Competition and Incentives with Motivated Agents," American Economic Review, June 2005, 95 (3), 616-636.

Dixit, Avinash, "Incentives and Organizations in the Public Sector: An Interpretative Review," Journal of Human Resources, Fall 2002, 37 (4), 696-727. Special Issue on Designing Incentives to Promote Human Capital.

\footnotetext{
${ }^{16}$ See Schnedler (2008) and Marisa Ratto and Schnedler (2008) for two recent contributions dealing with this problem.
} 
Easley, David and Maureen O'Hara, "The Economic Role of the Nonprofit Firm," The Bell Journal of Economics, August 1983, 14 (2), 531538.

Ellingsen, Tore and Magnus Johannesson, "Pride and Prejudice: The Human Side of Incentive Theory," American Economic Review, 2008, 98 (3), 990-1008.

Falk, Armin and Michael Kosfeld, "The Hidden Costs of Control," American Economic Review, 2006, 96 (5), 1611-1630.

Francois, Patrick, "Public Service Motivation' as an Argument for Government Provision," Journal of Public Economics, November 2000, 78 (3), 275-299.

Friebel, Guido and Wendelin Schnedler, "Team Governance: Empowerment or Hierarchical Control?" Discussion paper 3143, Institute for the Study of Labor (IZA), 2007.

Glaeser, Edward L. and Andrei Shleifer, "Not-for-Profit Entrepreneurs," Journal of Public Economics, July 2001, 81 (1), 99-115.

Gneezy, Uri and Aldo Rustichini, "A Fine is a Price," Journal of Legal Studies, 2000, 29 (1), 1-17.

Grossman, Sanford J. and Oliver D. Hart, "The Costs and Benefits of Ownership: A Theory of Vertical and Lateral Integration," Journal of Political Economy, 1986, 94, 691-719. 
Grout, Paul, "Investment and Wages in the Absence of Binding Contracts: A Nash Bargaining Approach," Econometrica, March 1984, 53 (2), 449 460.

Hansmann, Henry B., "The Role of Nonprofit Enterprise," Yale Law Journal, 1980, 89, 839-901.

Hart, Oliver, Firms, Contracts and Financial Structure, Oxford: Clarendon Press, 1995.

Hilborn, Robert C., "Sea Gulls, Butterflies, and Grasshoppers: A Brief History of the Butterfly Effect in Nonlinear Dynamics," American Journal of Physics, 2004, 72 (11), 425-427.

Holmström, Bengt, "Moral Hazard and Observability," Bell Journal of Economics, 1979, 10 (1), 74-91.

_ , "Moral Hazard in Teams," Bell Journal of Economics, 1982, 13 (2), 324340.

_, "Managerial Incentive Problems: A Dynamic Perspective," Review of Economic Studies, 1999, 66, 169-182.

_ and Paul Milgrom, "Multitask Principal-Agent-Analysis: Incentive Contracts, Asset Ownership, and Job Design," Journal of Law, Economics, and Organization, 1991, 7, 24-52. special issue.

_ and _ , "The Firm as an Incentive System," The American Economic Review, September 1994, 84 (4), 972-991. 
Klein, Robert G. Crawford Benjamin and Armen A. Alchian, "Vertical Integration, Appropriable Rents, and the Competitive Contracting Process," The Journal of Law and Economics, October 1978, 21, 297-326.

Ratto, Marisa and Wendelin Schnedler, "Too Few Cooks Spoil the Broth: Division of Labour and Directed Production," The B.E. Journal of Economic Analysis \& Policy, 2008, 8 (1, Topics), Article 27.

Schnedler, Wendelin, "When is It Foolish to Reward for A While Benefiting from B?," Journal of Labor Economics, 2008, 26 (4), 595-619.

- and Radovan Vadovic, "Legitimacy of Control." Discussion paper 3013, Institute for the Study of Labor (IZA), 2007.

Shavell, Steven, "Risk-Sharing and Incentives in the Principal-Agent Relationship," Bell Journal of Economics, 1979, 10 (1), 55-73.

Sliwka, Dirk, "On the Hidden Costs of Incentive Schemes," American Economic Review, 2007, 97 (3), 999-1012.

Wilson, James Q., Bureaucracy: What Governmental Agency Do and Why They Do It, New York: Basic Books, 1989.

\section{A Proofs}

Lemma 1. In equilibrium, the bureaucrat suggests a contribution $q \geq \delta(\theta) q^{A}$.

Proof. The proof works by contradiction. Suppose the bureaucrat offers a contribution that is not accepted: $q<\delta(\theta) q^{\mathrm{A}}$. Such an offer is strictly 
dominated by offering the contribution $q^{\mathrm{B}}$ if $q^{\mathrm{B}}(e) \geq \delta(\theta) q^{\mathrm{A}}$. Next, we deal with the case that $q^{\mathrm{B}}(e)<\delta(\theta) q^{\mathrm{A}}$. Recall that the utility of the bureaucrat is concave in $q$. Thus, the utility falls in $q$ for $q>q^{\mathrm{B}}(e)$ and hence it is strictly smaller at $q^{\mathrm{A}}(e)$ than at $\delta(\theta) q^{\mathrm{A}}$.

Lemma 2. The optimal choice of the worker either maximizes $u_{\theta}^{A}(e, w)$ or $u^{B}(e, w)$.

Proof. Proof by contradiction: say, the optimal effort level is $e$ and neither maximizes $u_{\theta}^{\mathrm{A}}(e, w)$ or $u^{\mathrm{B}}(e, w)$. First, take the case that $\delta(\theta) q^{\mathrm{A}} \geq q^{\mathrm{B}}(e)$. Then, the resulting utility is $u_{\theta}^{\mathrm{A}}(e, w)$ and a deviation to the maximizer of $u_{\theta}^{\mathrm{A}}$ is profitable because it yields at least $u_{\theta}^{\mathrm{A}}\left(e_{\theta}^{\mathrm{A}}, w\right)$ and even more if $u^{\mathrm{B}}\left(e_{\theta}^{\mathrm{A}}, w\right)>$ $u_{\theta}^{\mathrm{A}}\left(e_{\theta}^{\mathrm{A}}, w\right)$. The case $\delta(\theta) q^{\mathrm{A}} \geq q^{\mathrm{B}}(e)$ can be proven perfectly analogously.

Using this lemma, we can focus attention on the maximizers of the two utility functions $u^{\mathrm{A}}$ and $u^{\mathrm{B}}$. Because the utility when contributions are imposed by the authority increases in the arrival rate, a particularly simple situation occurs if the arrival rate is either particularly high or low.

Lemma 3. For $\theta=\infty$ (or $\delta=1), u_{\theta}^{A}(e, w)>u^{B}(e, w)$ for all efforts $e$.

Proof. If $\delta=1$, the contribution imposed by the authority is equal to its certainty equivalent for the manager: $\delta(\theta) q^{\mathrm{A}}(e)=q^{\mathrm{A}}(e)$. By assumption, this contribution exceeds the contribution by the unfettered bureaucrat $q^{\mathrm{B}}(e)$. Accordingly, $u^{\mathrm{A}}(e, w)>u^{\mathrm{B}}(e, w)$.

So for a high arrival rate, the worker's utility is described by $u^{\mathrm{A}}$ and the worker chooses $e_{\theta}^{\mathrm{A}}$. Similarly, no negotiation power (a low arrival rate) implies that the worker's utility amounts to $u^{\mathrm{B}}$. 
Lemma 4. For $\theta=0$ (or $\delta=0), u^{A}(e, 0, w)<u^{B}(e)$ for all efforts $e$.

Proof. If $\theta=0$, the required contribution $\delta(\theta) q^{\mathrm{A}}$ is zero and hence smaller than $q^{\mathrm{B}}$ for all effort levels. Accordingly, $u_{0}^{\mathrm{A}}(e, w)<u^{\mathrm{B}}(e, w)$.

So when the bureaucrat has dictatorial power, the worker chooses a maximizer $e^{\mathrm{B}}$. But how is the relationship between $u_{\theta}^{\mathrm{A}}$ and $u^{\mathrm{B}}$ affected by changes in $\theta$ ? In order to answer this question, we study the behavior of $u_{\theta}^{\mathrm{A}}$ in the arrival rate.

Lemma 5. $u_{\theta}^{A}\left(e_{\theta}^{A}, w\right)$ is continuously differentiable and increasing in $\theta$.

Proof. Observe that $\delta(\theta) q^{\mathrm{A}}(e)$ is a continuous differentiable function in $\theta$. Hence, $u_{\theta}^{\mathrm{A}}(e, w)=u\left(e, \delta(\theta) q_{\theta}^{\mathrm{A}}(e), w\right)$ is a continuously differentiable function in $\theta$ for fixed $e$. Moreover, $e_{\theta}^{\mathrm{A}}$ is also a continuously differentiable function in $\theta$. Overall, $u_{\theta}^{\mathrm{A}}\left(e_{\theta}^{\mathrm{A}}, w\right)$ is continuously differentiable and we can apply the envelope theorem to find its derivative: $\frac{d}{d \theta} u_{\theta}^{\mathrm{A}}\left(e_{\theta}^{\mathrm{A}}, w\right)=\frac{\partial}{\partial \theta} u_{\theta}^{\mathrm{A}}\left(e_{\theta}^{\mathrm{A}}, w\right)>0$. 


\begin{tabular}{|c|c|c|}
\hline Nr. & Author & "Title \\
\hline $08-17$ & $\begin{array}{l}\text { Paul Grout } \\
\text { Wendelin Schnedler }\end{array}$ & $\begin{array}{l}\text { Non-Profit Organizations in a Bureaucratic } \\
\text { Environment }\end{array}$ \\
\hline $08-16$ & $\begin{array}{l}\text { Clemens Kroneberg } \\
\text { Isolde Heintze } \\
\text { Guido Mehlkop }\end{array}$ & $\begin{array}{l}\text { On shoplifting and tax fraud: An action-theoretic } \\
\text { analysis of crime }\end{array}$ \\
\hline $08-15$ & $\begin{array}{l}\text { Hermann Jahnke } \\
\text { Dirk Simons }\end{array}$ & $\begin{array}{l}\text { A rationale for the payback criterion ñAn } \\
\text { application of almost stochastic dominance to } \\
\text { capital budgetingñ }\end{array}$ \\
\hline $08-14$ & $\begin{array}{l}\text { Peter Dürsch } \\
\text { Jörg Oechssler } \\
\text { Radovan Vadovic }\end{array}$ & Sick Pay Provision in Experimental Labor Markets \\
\hline $08-13$ & $\begin{array}{l}\text { Carsten Schmidt } \\
\text { Martin Strobel } \\
\text { Henning Oskar Volkland }\end{array}$ & $\begin{array}{l}\text { Accuracy, Certainty and Surprise - A Prediction } \\
\text { Market on the Outcome of the } 2002 \text { FIFA World } \\
\text { Cup }\end{array}$ \\
\hline $08-12$ & Mathias Sommer & $\begin{array}{l}\text { Understanding the trends in income, consumption } \\
\text { and wealth inequality and how important are } \\
\text { life-cycle effects? }\end{array}$ \\
\hline $08-11$ & $\begin{array}{l}\text { Hans Gersbach } \\
\text { Hans Haller }\end{array}$ & Club Theory and Household Formation \\
\hline $08-10$ & $\begin{array}{l}\text { Michael F. Meffert } \\
\text { Thomas Gschwend }\end{array}$ & $\begin{array}{l}\text { Strategic Voting in Multiparty Systems: A Group } \\
\text { Experiment }\end{array}$ \\
\hline 08-09 & $\begin{array}{l}\text { Jens Wüstemann } \\
\text { Jannis Bischof }\end{array}$ & $\begin{array}{l}\text { Ausweis von Finanzinstrumenten in europäischen } \\
\text { Bankbilanzen nach IFRS: Normative Erkenntnisse } \\
\text { empirischer Befunde }\end{array}$ \\
\hline $08-08$ & $\begin{array}{l}\text { Jürgen Eichberger } \\
\text { David Kelsey }\end{array}$ & Are the Treasures of Game Theory Ambiguous? \\
\hline $08-07$ & $\begin{array}{l}\text { Jürgen Eichberger } \\
\text { Ani Guerdjikova }\end{array}$ & Multiple Priors as Similarity Weighted Frequencies \\
\hline $08-06$ & $\begin{array}{l}\text { Jörg Oechssler } \\
\text { Andreas Roider } \\
\text { Patrick W. Schmitz }\end{array}$ & Cooling-Off in Negotiations - Does It Work? \\
\hline
\end{tabular}




\begin{tabular}{|c|c|c|}
\hline Nr. & Author & Title \\
\hline 08-05 & $\begin{array}{l}\text { Jörg Oechssler } \\
\text { Andreas Roider } \\
\text { Patrick W. Schmitz }\end{array}$ & Cognitive Abilities and Behavioral Biases \\
\hline 08-04 & Julian Rode & $\begin{array}{l}\text { Truth and trust in communication - Experiments on } \\
\text { the effect of a competitive context }\end{array}$ \\
\hline $08-03$ & Volker Stocké & $\begin{array}{l}\text { Educational Decisions as Rational Choice? An } \\
\text { Empirical Test of the Erikson-Jonsson Model for } \\
\text { Explaining Educational Attainment }\end{array}$ \\
\hline 08-02 & $\begin{array}{l}\text { Siegfried K. Berninghaus } \\
\text { Karl-Martin Ehrhart } \\
\text { Marion Ott }\end{array}$ & $\begin{array}{l}\text { Myopically Forward-Looking Agents in a Network } \\
\text { Formation Game: Theory and Experimental } \\
\text { Evidence }\end{array}$ \\
\hline 08-01 & $\begin{array}{l}\text { Sascha Huber } \\
\text { Thomas Gschwend } \\
\text { Michael F. Meffert } \\
\text { Franz Urban Pappi }\end{array}$ & $\begin{array}{l}\text { Erwartungsbildung über den Wahlausgang und ihr } \\
\text { Einfluss auf die Wahlentscheidung }\end{array}$ \\
\hline $07-76$ & $\begin{array}{l}\text { Michael Bremert } \\
\text { Dennis Voeller } \\
\text { Nicole Zein }\end{array}$ & $\begin{array}{l}\text { Interdependencies between Elements of } \\
\text { Governance and Auditing: Evidence from Germany }\end{array}$ \\
\hline $07-75$ & $\begin{array}{l}\text { Jannis Bischof } \\
\text { Jens Wüstemann }\end{array}$ & $\begin{array}{l}\text { How Does Fair Value Measurement under IAS } 39 \\
\text { Affect Disclosure Choices of European Banks? }\end{array}$ \\
\hline $07-74$ & $\begin{array}{l}\text { Markus Glaser } \\
\text { Philipp Schäfers } \\
\text { Martin Weber }\end{array}$ & $\begin{array}{l}\text { Managerial Optimism and Corporate Investment: Is } \\
\text { the CEO Alone Responsible for the Relation? }\end{array}$ \\
\hline $07-73$ & $\begin{array}{l}\text { Jannis Bischof } \\
\text { Michael Ebert }\end{array}$ & $\begin{array}{l}\text { IAS } 39 \text { and Biases in the Risk Perception of } \\
\text { Financial Instruments }\end{array}$ \\
\hline $07-72$ & $\begin{array}{l}\text { Susanne Abele } \\
\text { Garold Stasser }\end{array}$ & $\begin{array}{l}\text { Continuous and Step-level Pay-off Functions in } \\
\text { Public Good Games: A Conceptual Analysis }\end{array}$ \\
\hline 07-71 & $\begin{array}{l}\text { Julian Rode } \\
\text { Marc Le Menestrel }\end{array}$ & The role of power for distributive fairness \\
\hline $07-70$ & $\begin{array}{l}\text { Markus Glaser } \\
\text { Martin Weber }\end{array}$ & $\begin{array}{l}\text { Why inexperienced investors do not learn: They do } \\
\text { not know their past portfolio performance }\end{array}$ \\
\hline
\end{tabular}




\begin{tabular}{|c|c|c|}
\hline Nr. & Author & Title \\
\hline $07-69$ & $\begin{array}{l}\text { Jose Apesteguia } \\
\text { Steffen Huck } \\
\text { Jörg Oechssler } \\
\text { Simon Weidenholzer }\end{array}$ & $\begin{array}{l}\text { Imitation and the Evolution of Walrasian Behavior: } \\
\text { Theoretically Fragile but Behaviorally Robust }\end{array}$ \\
\hline $07-68$ & $\begin{array}{l}\text { Damian S. Damianov } \\
\text { Jörg Oechssler } \\
\text { Johannes Gerd Becker }\end{array}$ & $\begin{array}{l}\text { Uniform vs. Discriminatory Auctions with Variable } \\
\text { Supply - Experimental Evidence }\end{array}$ \\
\hline $07-67$ & $\begin{array}{l}\text { Dirk Simons } \\
\text { Barbara E. Weißenberger }\end{array}$ & $\begin{array}{l}\text { Die Konvergenz von externem und internem } \\
\text { Rechnungswesen ñKritische Faktoren für die } \\
\text { Entwicklung einer partiell integrierten } \\
\text { Rechnungslegung aus theoretischer Sichtñ }\end{array}$ \\
\hline $07-66$ & $\begin{array}{l}\text { Alexander Ludwig } \\
\text { Alexander Zimper }\end{array}$ & Attitude polarization \\
\hline $07-65$ & $\begin{array}{l}\text { Alexander Ludwig } \\
\text { Alexander Zimper }\end{array}$ & $\begin{array}{l}\text { A Parsimonious Model of Subjective Life } \\
\text { Expectancy }\end{array}$ \\
\hline $07-64$ & $\begin{array}{l}\text { Michael F. Meffert } \\
\text { Thomas Gschwend }\end{array}$ & $\begin{array}{l}\text { Voting for Coalitions? The Role of Coalition } \\
\text { Preferences and Expectations in Voting Behavior }\end{array}$ \\
\hline $07-63$ & $\begin{array}{l}\text { Michael F. Meffert } \\
\text { Thomas Gschwend }\end{array}$ & $\begin{array}{l}\text { Polls, Coalition Signals, and Strategic Voting: An } \\
\text { Experimental Investigation of Perceptions and } \\
\text { Effects }\end{array}$ \\
\hline $07-62$ & $\begin{array}{l}\text { Peter Dürsch } \\
\text { Maros Servátka }\end{array}$ & Risky Punishment and Reward in the Prisoner \\
\hline $07-61$ & $\begin{array}{l}\text { Wendelin Schnedler } \\
\text { Radovan Vadovic }\end{array}$ & Legitimacy of Control \\
\hline $07-60$ & Volker Stocké & $\begin{array}{l}\text { Strength, Sources, and Temporal Development of } \\
\text { Primary Effects of Families' Social Status on } \\
\text { Secondary School Choice }\end{array}$ \\
\hline $07-59$ & $\begin{array}{l}\text { Christopher Koch } \\
\text { Martin Weber } \\
\text { Jens Wüstemann }\end{array}$ & $\begin{array}{l}\text { Can Auditors Be Independent? - Experimental } \\
\text { Evidence }\end{array}$ \\
\hline
\end{tabular}

07-58 Sylvain Béal

PERCEPTRON VERSUS AUTOMATON\&8727; 